\title{
Chemical Modification of Poly(vinylacetylene) and Synthesis of Poly(1,2,3-triazole)s
}

\author{
Lian-jun Wang, ${ }^{\dagger, \ldots, *}$ Shan Liao, ${ }^{\ddagger}$ and Le-yong Wang ${ }^{\dagger}$ \\ 'School of Chemistry and Chemical Engineering, Nanjing University, Nanjing 210093, P. R. China \\ ${ }^{\star}$ College of Chemistry and Chemical Engineering, Hunan Institute of Engineering, Hunan 411104, P. R. China \\ ${ }^{*}$ E-mail: wangljchem@gmail.com \\ Received December 22, 2010, Accepted March 2, 2011
}

\begin{abstract}
A series of new polymers containing 1,2,3-triazoles were synthesized and their structures and properties were characterized by FT-IR, ${ }^{1} \mathrm{H}$ NMR, TGA, DSC and GPC. The results showed that the polymers modified by alkyl groups had good solubility, thermal stability and reasonable molecular weights. It was also demonstrated that the properties of fluorine-containing polymers were seriously affected by fluorine atoms with hydrophobic and chemical proof properties.
\end{abstract}

Key Words : Chemical modification, 1,2,3-Triazoles, Fluorinated polymers, Properties

\section{Introduction}

In recent years, there has been wide interests in click chemistry, an appealing concept proposed by Sharpless and co-workers, ${ }^{1}$ especially the copper-catalyzed Huisgen $1,3-$ dipolar cycloaddition of azides and terminal alkynes, the archetypal example of click chemistry. Since the objective of click chemistry would be to establish an ideal set of straightforward and highly selective reactions in synthetic chemistry, more and more researchers have been engaged in developing this strategy. In the field of polymer materials, click chemistry has been used for polymeric synthesis as well as the modification of surfaces nanometer- and mesoscale structures. ${ }^{2}$ Click reaction was used for synthesis of polymers containing 1,2,3-triazoles in the backbones from the monomers of dialkynes and diazides. For example, a new kind of glue was obtained with click chemistry by Diaz et $a .^{3}$ and a series of poly(alkyl aryl) ethers were synthesized with click chemistry reaction in our research group. ${ }^{4}$ And functional hyperbranched polymers were synthesized by click reaction from the monomers of triynes and diazides. ${ }^{5}$ When click reaction was applied in the chemical modification of polymers, many novel polymers were also obtained such as dendronized polymers, ${ }^{6}$ hydrogels, ${ }^{7}$ endfunctional polymers, ${ }^{8}$ and so on..

The preparation of Poly(vinylacetylene) (PVacet) was firstly reported by Kaneko et al. ${ }^{9}$ and then a few reports on PVacet were occurrence. ${ }^{10}$ To the best of our knowledge, however, no report on its thermal stability has been yet available. In fact, it would explode at $210^{\circ} \mathrm{C}$, which was demonstrated by thermogravimetric analysis in this report. So the pendent terminal alkynes in PVacet were used to react with azides via click reaction to get some modified polymers that we expected. In this paper, the thermal stability of PVacet and modified PVacet with pendent alkyl or fluoroalkyl groups were studied. Meanwhile, the 1,2,3-triazole rings grafted onto the substrate polymer may increase the antibacterial ability of novel polymers. ${ }^{11}$ And due to the characteristics of fluorine atoms, the enhanced appearance of fluorinated portions on the surfaces of fluorine-containing polymers is of importance in the potential applications as anti-thermal, water repellency, chemical proof, lubricant and electric insulation materials. ${ }^{12}$

\section{Experimental Part}

Materials. Triethylamine (TEA), tetrahydrofuran (THF), methanol $(\mathrm{MeOH})$ and acetonitrile $(\mathrm{MeCN})$ were distilled from $\mathrm{CaH}_{2}$. Chlorotrimethylsilane was distilled from $\mathrm{P}_{2} \mathrm{O}_{5}$. Magnesium turnings were treated with $5 \%$ aqueous hydrochloric acid for several minutes, washed with water, ethanol and ether successively, and dried at $120^{\circ} \mathrm{C}$ under vacuum for $4 \mathrm{~h}$. Other reagents were used as supplied. Trimethylsilyacetylene (TMSA) 1 was synthesized from commercial acetylene using literature procedures. ${ }^{13}$

Measurements. Infrared spectra were obtained on Thermo Electron Corporation Nicolet 380 FT-IR spectrophotometer. ${ }^{1} \mathrm{H}$ NMR $(400 \mathrm{MHz})$ was recorded on a Bruker AM-400 spectrometer with $\mathrm{Me}_{4} \mathrm{Si}\left({ }^{1} \mathrm{H}\right.$ NMR) as an internal standard. Relative molecular weights and molecular weight distributions were measured by gel permeation chromatography (GPC) system equipped with a Waters 1515 Isocratic HPLC pump, a Waters 2414 refractive index detector (RI), a Waters 2487 dual-wavelength $\lambda$ absorbance detector and a set of Waters Styragel columns (HR3, HR4 and HR5, $7.8 \times 300$ $\mathrm{mm})$. GPC measurements were carried out at $35^{\circ} \mathrm{C}$ using THF as an eluent with a $1.0 \mathrm{~mL} / \mathrm{min}$ flow rate. The system was calibrated with polystyrene standards. Differential scanning calorimetry (DSC) was conducted on a NetZSch (German) DSC 204 F1 system under nitrogen calibrated with indium and zinc standards. Thermogravimetric analysis (TGA) was performed on NetZSch (German) TGA 209 F1 system on powder samples at a heating rate of $10{ }^{\circ} \mathrm{C} / \mathrm{min}$ in $\mathrm{N}_{2}$ atmosphere.

Synthesis of PVacet 4. PVacet was prepared through three steps and the detailed procedures were reported by Helms. ${ }^{6}$ 
Polymer 3: white powder (80\%). IR $\left(\mathrm{KBr}, \mathrm{cm}^{-1}\right): v 2959$, 2917, 2899, 2852, 2168, 1944, 1865, 1447, 1407, 1350, 1250, 1098, 841, 759, 698, 638; ${ }^{1} \mathrm{H}$ NMR (400 MHz, $\mathrm{CDCl}_{3}$, ठ): 2.9-2.6 (1H, br), 1.6-1.2 (2H, br), $0.2(9 \mathrm{H}, \mathrm{s})$.

Polymer 4: pale yellow powder $(72 \%)$. IR $\left(\mathrm{KBr}, \mathrm{cm}^{-1}\right)$ : $v$ 3299, 2928, 2856, 2113, 1629, 1448, 1363, 1253, 1098, 848, 630; ${ }^{1} \mathrm{H}$ NMR (400 MHz, $\left.\mathrm{CDCl}_{3}, \delta\right): 3.2-2.7$ (1H, br), 2.12 $(1 \mathrm{H}, \mathrm{s}), 1.9-1.4(2 \mathrm{H}, \mathrm{br}) . \mathrm{Mn}=30150, \mathrm{Mw}=69600, \mathrm{PDI}=$ 2.31 .

Synthesis of Alkyl and Fluoroalkyl Azides from Halides 5a-c. To a $50 \mathrm{~mL}$ three-necked flask equipped with a magnetic stirrer, a thermometer and a condenser were added alkyl bromide or fluoroalkyl iodide ( $5 \mathrm{mmol}$ ), $\mathrm{NaN}_{3}(390$ $\mathrm{mg}, 6 \mathrm{mmol}$ ) dissolved in $10 \mathrm{~mL}$ water and Tetrabutylammonium bromide ( $32 \mathrm{mg}, 2 \mathrm{~mol} \%$ ). The reaction mixture was stirred at $90^{\circ} \mathrm{C}$ for $24 \mathrm{~h}$ and then cooled to room temperature, and extracted with ether $(3 \times 10 \mathrm{~mL})$. The organic phase was dried over $\mathrm{MgSO}_{4}$, filtered, and concentrated. The products 5a-c were obtained by flash chromatography based on gel silca with petroleum ether/ethyl acetate (10:1 v/v) as the eluent.

Compound 5a: colorless liquid (450 mg, 91\%). IR (KBr, $\left.\mathrm{cm}^{-1}\right)$ : n 2962, 2925, 2854, 2103, 1629, 1458, 1412, 1260, 1094, 1019, 863, 800; ${ }^{1} \mathrm{H}$ NMR (400 MHz, $\left.\mathrm{CDCl}_{3}, \delta\right): 3.47$ $(2 \mathrm{H}, \mathrm{m}, J=7.01 \mathrm{~Hz}), 1.55(2 \mathrm{H}, \mathrm{m}, J=6.72 \mathrm{~Hz}, J=7.54 \mathrm{~Hz})$, $1.38(2 \mathrm{H}, \mathrm{m}, J=7.01 \mathrm{~Hz}, J=7.54 \mathrm{~Hz}), 0.93(3 \mathrm{H}, \mathrm{m}, J=6.68$ $\mathrm{Hz})$.

Compound 5b: colorless liquid (713 mg, 92\%). IR ( $\mathrm{KBr}$, $\left.\mathrm{cm}^{-1}\right): v 2926,2857,2096,1555,1459,1374,1260,1104$, 1023, 804; ${ }^{1} \mathrm{H}$ NMR (400 MHz, $\left.\mathrm{CDCl}_{3}, \delta\right): 3.25$ (2H, m, $J=$ $7.01 \mathrm{~Hz}), 1.58(2 \mathrm{H}, \mathrm{m}, J=7.01 \mathrm{~Hz}, J=7.53 \mathrm{~Hz}), 1.35(10 \mathrm{H}$, $\mathrm{m}), 0.89(3 \mathrm{H}, \mathrm{t}, J=7.01 \mathrm{~Hz})$.

Compound 5c: white solid (2.32 g, 95\%). IR ( $\left.\mathrm{KBr}, \mathrm{cm}^{-1}\right)$ : v 2960, 2922, 2856, 2109, 1629, 1444, 1343, 1206, 1151, 1079, 1066, 986, 921, 882, 711; ${ }^{1} \mathrm{H}$ NMR (400 MHz, $\mathrm{CDCl}_{3}$, $\delta): 3.62(2 \mathrm{H}, \mathrm{m}, J=7.01 \mathrm{~Hz}), 2.55(2 \mathrm{H}, \mathrm{m}, J=7.01 \mathrm{~Hz})$.

Synthesis of 2,2,2-trifluoroethyl Azide 5d. Methanesulfonyl chloride (228 mg, $2 \mathrm{mmol}$ ) was slowly dropped, under a nitrogen atmosphere, to a dichloride methane solution $(30 \mathrm{~mL})$ of trifluoroethanol $(200 \mathrm{mg}, 2 \mathrm{mmol})$ and triethylamine $(10 \mathrm{mg}, 5 \mathrm{~mol} \%)$ at $-5{ }^{\circ} \mathrm{C}$. After complete methanesulfonation $(4 \mathrm{~h})$, the solvent was removed by rotary evaporation. Then, to this system, $\mathrm{NaN}_{3}(143 \mathrm{mg}, 2.2 \mathrm{mmol}$ ), DMSO (30 mL) and 18-crown-6 (27 mg, $5 \mathrm{~mol} \%)$ were added, and stirred at $110{ }^{\circ} \mathrm{C}$ for $20 \mathrm{~h}$. The reaction mixture was diluted with ether $(50 \mathrm{~mL})$ and washed with brine $(3 \times$ $10 \mathrm{~mL})$ followed by water $(3 \times 10 \mathrm{~mL})$. The organic phase was dried over $\mathrm{MgSO}_{4}$, filtered, and concentrated. The product 5d was obtained by flash chromatography based on gel silca with petroleum ether/ethyl acetate $(10: 1 \mathrm{v} / \mathrm{v})$ as the eluent. $^{14}$

Compound 5d: pale brown liquid (208 mg, 85\%). IR $\left(\mathrm{KBr}, \mathrm{cm}^{-1}\right)$ : v 2960, 2922, 2856, 2109, 1629, 1444, 1343, $1206,1151,1079,1066,986,921,882,711 ;{ }^{1} \mathrm{H}$ NMR (400 $\left.\mathrm{MHz}, \mathrm{CDCl}_{3}, \delta\right): 3.85$ (2H, dd).

Chemical Modification of Polymers. To a $25 \mathrm{~mL}$ flask equipped with a magnetic stirrer were added PVacet (30 mg,
$0.58 \mathrm{mmol})$ and organic azide $(0.58 \mathrm{mmol})$ dissolved in 8 $\mathrm{mL}$ THF. Under vigorously stirring, $\mathrm{CuSO}_{4} \cdot 5 \mathrm{H}_{2} \mathrm{O}(7 \mathrm{mg}, 5$ mol \%) and sodium ascorbate (12 $\mathrm{mg}, 10 \mathrm{~mol} \%$ ) dissolved in $8 \mathrm{~mL} \mathrm{H}_{2} \mathrm{O}$ were added, then stirred for $12 \mathrm{~h}$ at room temperature. The reaction mixture was poured into hexane, and the precipitate was washed with ammonia and water for several times. Finally, the products were dried at $60^{\circ} \mathrm{C}$ under vacuum for $48 \mathrm{~h}$.

Compound 6a: pale solid powder (64 mg, 73\%). IR (KBr, $\left.\mathrm{cm}^{-1}\right)$ : v 3131, 3063, 2958, 2934, 2873, 1637, 1542, 1458, 1380, 1336, 1247, 1216, 1146, 1095, 1051, 835, 802, 757; ${ }^{1} \mathrm{H}$ NMR (400 MHz, $\left.\mathrm{CDCl}_{3}, \delta\right): 6.9-7.2(1 \mathrm{H}, \mathrm{br}), 1.4-1.1$ (2H, br), 4.4-3.9 (2H, br), 2.4-2.1 (1H, br), 1.9-1.5 (4H, br), $1.0-0.8(3 \mathrm{H}, \mathrm{br}) ; \mathrm{Mn}=51230, \mathrm{Mw}=135800, \mathrm{PDI}=2.65$.

Compound 6b: pale solid powder (76 mg, 64\%). IR ( $\mathrm{KBr}$, $\left.\mathrm{cm}^{-1}\right)$ : v 3125, 3064, 2927, 2856, 1631, 1538, 1458, 1340, 1261, 1216, 1152, 1105, 1045, 906, 858, 803, 726; ${ }^{1} \mathrm{H}$ NMR (400 MHz, $\left.\mathrm{CDCl}_{3}, \delta\right): 7.2-6.8$ (1H, br), 4.4-4.0 (2H, br), 2.42.1 (1H, br), 2.0-1.5 (2H, br), 1.5-1.0 (12H, br), 1.0-0.7 (3H, br); $\mathrm{Mn}=63856, \mathrm{Mw}=175600, \mathrm{PDI}=2.75$.

Compound 6c: yellow solid powder (186 mg, 60\%). IR $\left(\mathrm{KBr}, \mathrm{cm}^{-1}\right): v$ 3124, 3060, 2945, 2855, 1635, 1457, 1212, 1151, 992, 841, 808, 737.

Compound 6d: yellow solid powder (62 mg, 80\%). IR $\left(\mathrm{KBr}, \mathrm{cm}^{-1}\right): v 3125,3061,2933,2855,2109,1636,1457$, 1396, 1336, 1266, 1170, 1096, 1046, 930, 838, 798.

\section{Results and Discussion}

Synthesis and Characterization of PVacet. PVacet was prepared according to the literature procedures (Scheme 1). ${ }^{6}$ First, compound $\mathbf{2}$ was synthesized by the Sonogashira coupling reaction ${ }^{15}$ between vinyl bromide and trimethylsilylacetylene (TMSA) in which $5 \mathrm{~mol} \% \mathrm{Pd}\left(\mathrm{PPh}_{3}\right)_{2} \mathrm{Cl}_{2}$ was used as a typical palladium catalyst, $10 \mathrm{~mol} \% \mathrm{CuI}$ as a cocatalyst, and triethylamine as a solvent with a yield of $60 \%$. Then, the monomer 2 was polymerized in bulk at $60^{\circ} \mathrm{C}$ with AIBN. No fraction of the TMS-protected polymer $\mathbf{3}$ was performed in this procedure, which resulted in broader polydispersity than that described in the literature. Finally, the polymer 3 was dissolved in THF and deprotected under aqueous $\mathrm{KOH}$ to produce polymer 4 containing pendent alkynes.

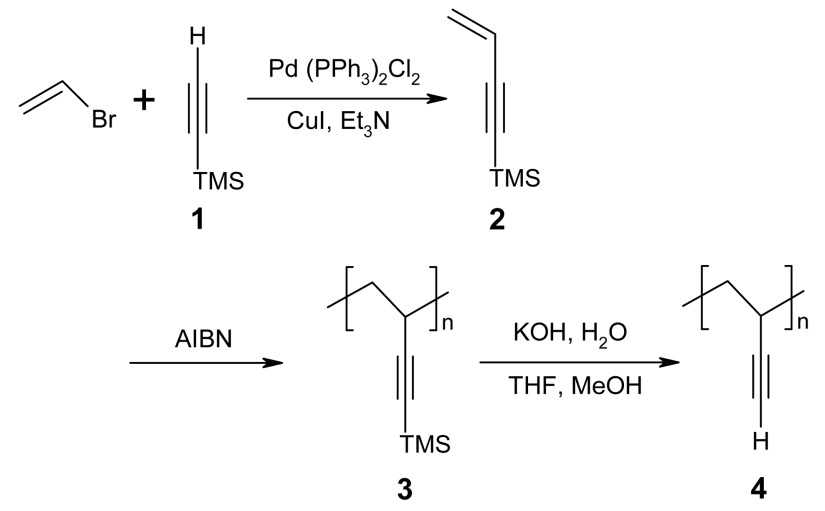

Scheme 1. Synthesis of PVacet. 


$$
\begin{array}{ll}
\mathrm{RX}+\mathrm{NaN}_{3} \frac{\mathrm{PTC} / \mathrm{H}_{2} \mathrm{O}}{90^{\circ} \mathrm{C}} & \mathrm{RN}_{3} \\
\text { a, } \mathrm{R}=\mathrm{CH}_{3}\left(\mathrm{CH}_{2}\right)_{3}, \mathrm{X}=\mathrm{Br} & \mathbf{5 a - c} \\
\text { b, } \mathrm{R}=\mathrm{CH}_{3}\left(\mathrm{CH}_{2}\right)_{7}, \mathrm{X}=\mathrm{Br} & \\
\text { c, } \mathrm{R}=\mathrm{CH}_{3}\left(\mathrm{CF}_{2}\right)_{7} \mathrm{CH}_{2} \mathrm{CH}_{2}, \mathrm{X}=\mathrm{I}
\end{array}
$$

Scheme 2. Synthesis of organic azides.

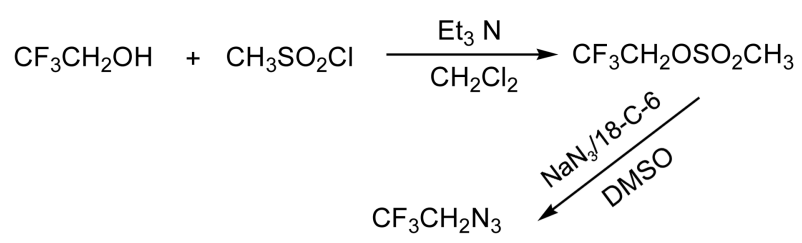

$5 d$

Scheme 3. Synthesis of azido trifluoroethane.

Synthesis of Organic Azides. Organic azides can be prepared from halides, alcohols, amines or hydrazines. ${ }^{16}$ Here, the azides 5a-c were synthesized through modification of literature procedures ${ }^{17}$ in $85-95 \%$ yields by halides (Scheme 2). In the reactions performed in our lab, rather than organic solvent, only water was added and tetrabutylammonium bromide was used as a kind of phase transfer catalyst (PTC), which resulted in a little higher yields and easy purification. As for the preparation of compound 5d, two steps were required with 2,2,2-trifluoro- ethanol as the original material (Scheme 3). At first, the intermediate, methylsulfonyl ramification was formed, and then the resulting ramification reacted with $\mathrm{NaN}_{3}$ without further purification. ${ }^{18}$

Chemical Modification of PVacet. The chemical modification of PVacet were carried out in a 1:1 solvent ratio of water to THF using $5 \mathrm{~mol} \% \mathrm{CuSO}_{4} \cdot 5 \mathrm{H}_{2} \mathrm{O}$ and $10 \mathrm{~mol} \%$ sodium ascorbate (Scheme 4). Usually, the click reactions were performed smoothly at room temperature. When we raised the temperature to $60^{\circ} \mathrm{C}$, the reaction would be completed in an hour, but the resultant molecular weight distribution was not as good as what we had got at room temperature. The difference of the isolated yields of polymers 6a-d might be attributed to the bulk effect of azides: the larger the volume of organic azide was, the lower the yield could be. The change of the color of the solution, from orange yellow to blue green, was a simple signal for the completion of the reaction.

\section{Properties of Polymers.}

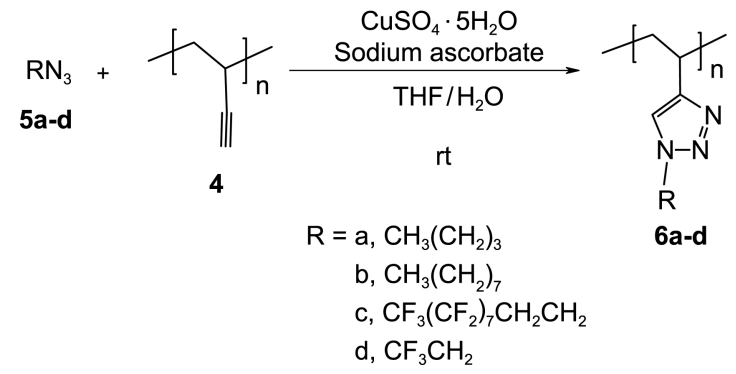

Scheme 4. Modification of polymers by click chemistry.
Table 1. Solubility of PVacet and the modified polymers

\begin{tabular}{ccccccc}
\hline Polymers & Acetone & THF & $\mathrm{CHCl}_{3}$ & NMP & DMSO & DMF \\
\hline $\mathbf{4}$ & + & + & + & + & + & + \\
$\mathbf{6 a}$ & + & + & + & + & + & + \\
$\mathbf{6 b}$ & + & + & + & + & + & + \\
$\mathbf{6 c}$ & - & - & - & $\mathrm{s}$ & $\mathrm{s}$ & $\mathrm{s}$ \\
$\mathbf{6 d}$ & - & - & - & - & - & - \\
\hline
\end{tabular}

Note: (+), soluble; (s), swell; (-), insoluble.

Table 2. Physical properties of PVacet and the modified polymers

\begin{tabular}{cccccc}
\hline Polymers & $\mathrm{Mn}^{a}$ & $\mathrm{Mw}^{a}$ & $(\mathrm{Mw} / \mathrm{Mn})^{a}$ & $\mathrm{~T}_{\mathrm{g}}{ }^{b}\left({ }^{\circ} \mathrm{C}\right)$ & $\mathrm{T}_{\mathrm{d}}{ }^{b}\left({ }^{\circ} \mathrm{C}\right)$ \\
\hline $\mathbf{4}$ & 30150 & 69600 & 2.31 & 52 & 210 \\
$\mathbf{6 a}$ & 51230 & 135800 & 2.65 & 86 & 314 \\
$\mathbf{6 b}$ & 63860 & 175600 & 2.75 & - & 287 \\
$\mathbf{6 c}$ & - & - & - & 65 & 336 \\
$\mathbf{6 d}$ & - & - & - & - & 439 \\
\hline
\end{tabular}

${ }^{a} \mathrm{GPC}$ in THF (0.1 wt \%) vs. polystyrene at $35^{\circ} \mathrm{C} .{ }^{b} \mathrm{DSC}$ and TGA at 10 ${ }^{\circ} \mathrm{C} / \mathrm{min}$ in $\mathrm{N}_{2}$ atmosphere.

Solubility of Polymers: From the solubility tests of polymers (Table 1), we can see that polymers $\mathbf{6 a}$ and $\mathbf{6 b}$ possessed good solubility which might be the result of grafting flexible pendent groups onto substrate polymer, but polymers $\mathbf{6 c}$ and $\mathbf{6 d}$ containing fluorine atoms were not able to be dissolved in most organic solvents such as acetone, THF, $\mathrm{CHCl}_{3}$, DMF, and so on. Polymer $6 \mathbf{c}$ only could be swollen in the polar solvents, and $\mathbf{6 d}$ could be dispersed homogenously in the polar solvents, but it would subside after keeping immobile for a period of time. The chemical proof property of modified polymers $\mathbf{6 c}$ and $\mathbf{6 d}$ might be illustrated that the pendent fluorinated groups, like a sheath, protected the backbones of polymers from the attack of organic solvents.

Molecular Weights and Their Distributions of Polymers: The molecular weights and their distributions of PVacet and modified polymers were listed in the Table 2 . It can be seen that the molecular weights of modified polymers $\mathbf{6 a}$ and $\mathbf{6 b}$, determined by GPC, became larger and the molecular weight distributions became a little broader. Furthermore, the molecular weights of polymers became heavier with the increase of the molecular weights of pendent chains, which was similar to what was described by Helms. ${ }^{7}$ However, fluorinated polymers $\mathbf{6 c}$ and $\mathbf{6 d}$ couldn't be characterized by GPC because of their insolubility in organic solvents such as acetone, THF, DMF, and so on.

Thermal Stability of Polymers: The thermal stability of each polymer were examined with dynamic thermogravimetric analysis (TGA) at a heating rate of $10^{\circ} \mathrm{C} / \mathrm{min}$ (Fig. 1). Corresponding decomposed temperatures $\left(\mathrm{T}_{\mathrm{d}}\right)$ were listed in the Table 2. It should be noted that the substrate polymer, PVacet showed a volatile weight loss at about $210^{\circ} \mathrm{C}$. To demonstrate this exploding case, a small block of PVacet was placed in a Bunsen burner flame and it blew up with a "pu" sound. However, all the modified polymers displayed good thermal stability. The fluorinated polymers $\mathbf{6 c - d}$ ex- 


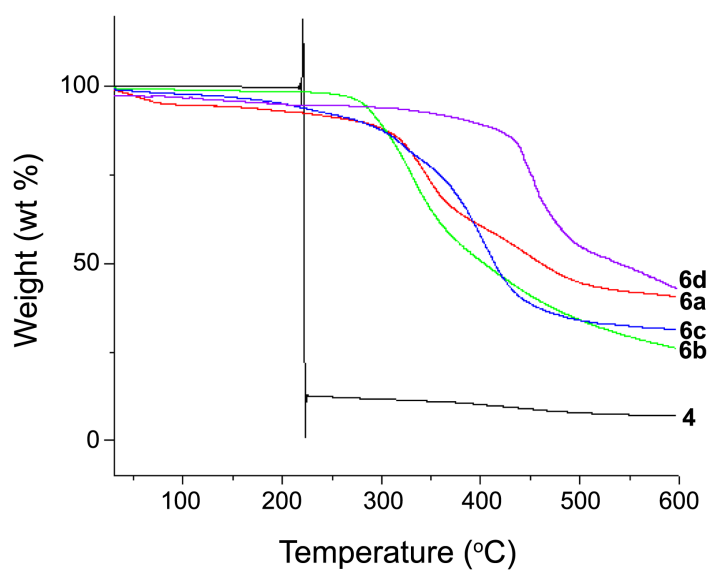

Figure 1. TG curves of polymers.

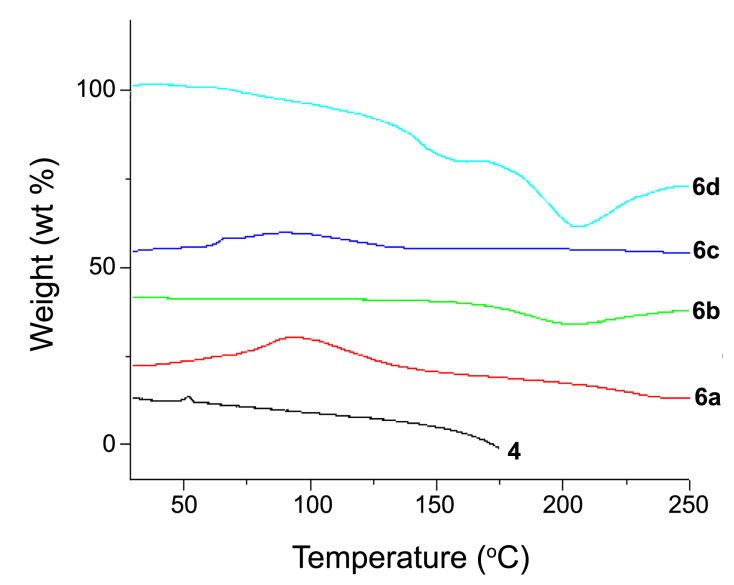

Figure 2. DSC curves of polymers with endo direction.

hibited higher $T_{d}$ value than those of the polymers 6 a-b because of the stronger interchain interactions of the $-\mathrm{CF}_{3}$ groups. The polymer 6d exhibited much higher $T_{d}$ value than that of the polymer $\mathbf{6 c}$, and this was attributed to the longer fluorine-containing pendant chains in the polymer $\mathbf{6 d}$.

The series of polymers were subjected to different scanning calorimetry (DSC), and the results of these experiments are shown in Figure 2 and Table 2. The polymers showed weak glass transitions, some of which could not be assigned unambiguously. Because of the instability of the substrate polymer 4 , the terminal measurement temperature was stopped at $180{ }^{\circ} \mathrm{C}$, before which there was no occurrence of crystallization peak or melting peak in DSC curve. The $\mathrm{T}_{\mathrm{g}}$ 's values of polymers $\mathbf{6 a}$ and $\mathbf{6 c}$ were higher than that of the precursor 4, which was attributable to the rigid properties of 1,2,3-triazole rings. Exothermic peaks were observed on the curves of polymers $\mathbf{6 b}$ and $\mathbf{6 d}$ from $150{ }^{\circ} \mathrm{C}$ to $230^{\circ} \mathrm{C}$, and this might be attributed to the cooling crystallization of the long pendant units.

\section{Conclusions}

PVacet was prepared through three steps from TMSA, and then it was modified via click reaction with the introduction of alkyl or fluoroalkyl groups to the pendent alkynes of the polymer. The solubility of alkyl-modified polymers was the same as PVacet, but the thermal stability was greatly improved. Fluoroalkyl-modified polymers, with excellent thermal stability and solvent- repelling, could have potential applications as anti-thermal, water repellency and chemical proof materials.

\section{References}

1. Kolb, H. C.; Finn, M. G.; Sharpless, K. B. Angew. Chem. Int. Edit. 2001, 40, 2004.

2. For reviews see: (a) Lutz, J. F. Angew. Chem. Int. Edit. 2007, 46, 1018. (b) Binder, W. H.; Sachsenhofer, R. Macromol. Rapid Comm. 2007, 28, 15. (c) Nandivada, H.; Jiang, X.; Lahann, J. $A d v$. Mater. 2007, 19, 2197. (d) Fournier, D.; Hoogenboom, R.; Schubert, U. S. Chem. Soc. Rev. 2007, 36, 1369.

3. Diaz, D. D.; Punna, S.; Holzer, P.; Mcpherson, A. K.; Sharpless, K. B.; Fokin, V. V.; Finn, M. G. J. Polym. Sci. Pol. Chem. 2004, $42,4392$.

4. Zhu, Y. Q.; Huang, Y. G.; Meng, W. D.; Li, H. Q.; Qing, F. L. Polymer 2006, 47, 6272.

5. Haussler, M.; Qin, A. J.; Tang, B. Z. Polymer 2007, 48, 6181.

6. Chang, Z. J.; Xu, Y.; Zhao, X.; Zhang, Q. H.; Chem, D. J. Appl. Mater. Interfaces 2009, 12, 2804.

7. Ossipov, D. A.; Hilborn, J. Macromolecules 2006, 39, 1709.

8. Lutz, J. F.; Borner, H. G.; Han, K. Macromol. Rapid Comm. 2005, 26,514 .

9. Kaneko, I.; Hagihara, N. Polym. Lett. 1971, 9, 275.

10. (a) Mavinkurve, A.; Visser, S.; VandenBroek, W.; TerBrugge, F.; Pennings, A. J. Eur. Polym. J. 1997, 33, 719. (b) Mavinkurve, A.; Visser, S.; VandenBroek, W.; Pennings, A. J. J. Polym. Sci. Pol. Chem. 1996, 34, 985.

11. Holla, B. S.; Mahalinga, M.; Karthikeyan, M. S.; Poojary, B.; Akberali, P. M.; Kumari, N. S. Eur. J. Med. Chem. 2005, 40, 1173.

12. (a) Reisinger, J. J.; Hillmyer, M. A. Prog. Polym. Sci. 2002, 27 , 971. (b) Imae, T. Curr. Opin. Colloid In. 2003, 8, 307.

13. Holmes, A. B.; Sporikou, C. N. Org. Synth. 1987, 65, 61.

14. Wu, Y. M.; Deng, J.; Fang, X.; Chen, Q. Y. J. Fluorine Chem. 2004, $125,1415$.

15. Sonogashira, K.; Tohda, Y.; Hafihara, N. Tetrahedron Lett. 1975, 16, 4467.

16. Scriven, E. F. V.; Turnbull, K. Chem. Rev. 1988, 88, 297.

17. Boyer, J. H.; Hammer, J. J. Am. Chem. Soc. 1955, 77, 951.

18. Caution: Be careful in the operation of organic azides which were facile to explode. Don't evaporate to dryness in the process of rotary evaporation! 